\title{
THE RELATIONSHIP BETWEEN ADVISORY WORK AND RESEARCH IN AGRICULTURE ${ }^{1}$ )
}

\author{
G. J. VERVELDE \\ Ministry of Agriculture, Fisheries and Food, The Hague
}

\section{RESEARCH AND FARMERS' PROBLEMS}

Hardly a government exists that is not concerned in agricultural progress. lirogress depends on a number of physical and economic conditions, but also requires theoretical knowledge, inventiveness, practical experience and knowledge of the actual situation. These personal factors are required in different proportions, depending on the type of improvement to be made. Theoretical knowledge and inventiveness are qualities one may expect in research workers. On the other hand, farmers are well-known for their practical experience and knowledge of the situation on their farms.

There are two types of problems in practical agriculture.

a Specific problems. These continue to arise in great numbers. They can be attributed to very definite causes, such as many diseases in crops and animals, or can be described either as well-defined imperfections, such as defects in the quality of agricultural produce, trouble with machinery and equipment, or as concrete questions, e.g., the right amount of nitrogen for a certain crop.

b General problems, such as labour shortage, unsatisfactory results of the farm as a whole or of certain details of the farming enterprise, new tasks imposed on the farmer by political or economic necessities.

The problems of the second kind may, upon investigation, appear to belong to the first category, but this is not always so. In this case it is necessary to consider the structure of the farm as a whole, or the details involved.

In many of the simpler cases all that is required is a certain amount of brainwork and ingenuity on the part of the farmer. There remain, however, quite a number of other cases. For these there are two possibilities:

a previous research may have provided some kind of solution which has only to be brought to light and adapted,

b the problem requires new, original research.

In both cases even educated farmers cannot be expected to possess sufficient knowledge of the store of information already available, or to be able to formulate their problems in terms of the scientific research required. For these and other purposes in nearly all countries advisory services are available in which university-trained agriculturists and horticulturists hold the highest positions. They have been given the position of intermedairy between practice and research. This does not mean, however, that the farmer and the research bodies are the only two parties that really matter, the advisory service being a more or less passive link between them. The advisory service certainly has a creative task, and in order to accomplish it they should be supported and accepted by both research workers and farmers.

1) Received for publication March 3, 1956. 
In order to be of any help to farmers and gardeners, the advisory service has to combine all the qualities mentioned in the beginning of this paragraph: theoretical knowledge, inventiveness, practical experience and insight into the actual situation. Each of these qualities can be developed by a different type of research. Theoretical knowledge is increased by factorial research, inventiveness is indispensable in developmental research, practical experience is gained by empirical research, and the actual situation can be studied by means of operational research. These 4 types of research, plus a fifth less well-defined type, preliminary research, cover the whole field of agricultural research.

\section{THE DIFFERENT TYPES OF RESEARCH}

a Preliminary or exploratory research: the first steps taken to tackle a problem. It usually consists in finding out what is roughly known about a problem, what factors may be involved, and what practical possibilities apparently exist for eradicating the trouble.

b Factorial research: an analytical study of the part played by individual factors in some phenomenon or process, i.e. a study of relationships. The effect of any single factor may be studied, but it may also be necessary to study the factors in combination in order to find the interactions. The factors may correspond to some practical treatment (nitrogen dressing, time of sowing), in which case the results of factorial research have direct applicability. In most cases the factors are defined in such a way as to give the best possible description and explanation of the process or phenomenon, such as the botanical analysis of grassland, the mineral composition of crops, the percentage of pore space in soils. The results then give no direct information on practical measures to be taken.

c Developmental research commences when it is required to determine the best methods of handling factors of which the effects have been established by factorial research. Thus, it has been known for more than 20 years that $\mathrm{pH}$ is a determining factor in conserving vegetable material, yet investigations into the different methods of obtaining low $\mathrm{pH}$ still continue. Successful developmental research indicates what practical measures are required.

d Empirical research. This type of research, quite common in agriculture, does not start from knowledge of the factors involved, but from what seem to be practical possibilities (trial and error method). Thus, if some quality defect is to be eliminated, it is possible to test whether the desired effect can be obtained by using a different type of manure or fertilizer.

e Surveys, questionnaires, variety tests, routine testing of soils and seeds can all be considered as a kind of operational research, that is, an assembling of data on the actual situation as a basis for action.

\section{THE TASK OF THE ADVISORY SERVICE IN AGRICULTURAL RESEARCH}

As most farmers' problems are recognized by the advisory officer or referred to him in the first place, he is the first to analyse the problem and consider remedies. In quite a number of cases he will be able to suggest measures to be taken. In other cases a few simple experiments by the advisory service will provide the answer. They will be directed to practical measures rather than 
to the elucidation of the underlying factors, and thus they come under either the empirical research or the development research group.

In other cases the problem may be more complex and require special research. Even then the advisory service may be in the best .position to carry out this research, especially if the problem is not of a national character and the investigation involves a number of field experiments.

But even if the problem has to be taken over by a research institute, the aid of the advisory officer who carried out the preliminary research should be enlisted in planning the project and the ensuing activities, if only in a consultative position. In the Netherlands there have been many instances of substantial improvements in farming practices originating from ideas put forward by advisory officers.

Likewise, in the case of research that was not begun in order to solve urgent problems, but is undertaken for its own sake, the advisory officer may play a very useful part by giving his opinion on the practicability of possible treatments or measures investigated.

The task of the advisory service with respect to research does not end here. There are research activities, such as testing crop varieties, that are best undertaken by research stations with a specialized staff, but require experiments in many different places scattered over the country. Other investigations by research institutes require work on commercial farms, e.g. when farm management, labour problems or economic questions are involved. In these cases co-operation between the research institute and the advisory service, the latter doing the local work, will not only ensure that the investigations are carried out under the most suitable local conditions, but also an immediate application of the results by the advisory staff taking part in the work. A number of projects of this type have been organized in this way in the Netherlands. They are called "inter-provincial series". Such series usually come under the headings of developmental and empirical research, but in some cases they may be of the factorial type.

There are other advantages in organizing research in this way. The experiments can also be used for demonstration purposes. The staff detailed to perform and supervise the experiments gain experience in new methods tested in the experiments. The research task keeps the advisory staff abreast of research developments and also enables them to adopt a critical attitude towards anything advocated as an improvement.

The various research activities of the advisory service have their own special needs. The advisory officer should have a small number of assistants and the necessary equipment for carrying out the research work. In some cases the advisory officer may be the director of a small regional research station. An experimental farm will be very useful, but it is also possible to arrange with some farmer for a number of experiments to be centred on his farm.

It is useful to arrange for a committee, in which the central institutes are represented, to examine proposals for new research made by various districts of the advisory service. This prevents trivial problems from taking up too much time and effort. Moreover, if some problem is found to have arisen in several districts at the same time, the problem may be earmarked as the responsibility of one specific institute. It is useful to collect in an annual index 
research projects carried out in the various districts. No conclusions should be drawn from a small number of local experiments if similar experiments have been carried out elsewhere. It is probably one of the few defects of the system of decentralized research in the advisory districts that the experiments sometimes lead to rash conclusions based on the evidence of too little experimental data. Registration, classification and publication of all local and central research projects are means of informing all parties concerned of research elsewhere that is related to their own work.

There is one final research task for the advisory staff. They have to ensure that the results of agricultural research are applied under conditions for which the results are valid and on farms where the application is economical. In simple cases it will be possible to instruct the farmer how to decide for himself what action should be taken. In other cases the farmer may not have means of evaluating the situation and the local advisory officer may then be in the best position to perform this type of "operational" research, probably by means of a survey, questionnaire or the like. Under this heading come research programs such as : the possibility of tile drainage, the frequency of drought damage in connection with supplementary irrigation, and the incidence of mineral deficiences in crops and animals.

\section{THE TASK OF THE RESEARCH INSTITUTES WITH RESPECT TO THE ADVISORY SERVICE}

It has already been mentioned that the institutes for agricultural research will be well advised to secure the co-operation of advisory officers in planning or performing research activities intended for immediate practical application. Most of the results, however, have to be elaborated and examined in a highly specialized manner and the conclusions are formulated in technical professional terms which are not readily understood by less specialized workers. The same applies to basic research. Thus there is a very clear task for the research bodies in making the results available to the staff of the advisory service. If they value a speedy application of scientific knowledge - and who does not? - it should be presented in such a form that it can be used by a sufficient number of persons whose task it is to promote progress in practice. They should not have to obtain the information by struggling through a bewildering mass of scientific papers. The research authorities, like good salesmen, should consider it their duty to present the information in a palatable and readily comprehensible form. Several methods are possible: the results can be recorded in papers or bulletins, courses can be arranged or demonstrations can be given. In all cases it will be advisable to have special officers in charge of this dissemination work. Whether they should be on the staff of the research institute or belong to the advisory service personnel is not very material. The best plan would probably be to employ these officials in the advisory service in countries where the farming practices lag far behind available scientific knowledge. As soon as the gap has been closed it may be sound policy to engage them in the research institutes.

It should be stressed that new results of basic research may be just as useful to the advisory officer as the results of applied research, inasmuch as they point out principles and relationships and thus help to classify existing knowledge and experience, and they may also explain facts which previously had 
to be accepted as empirical knowledge. It would seem that with the recent rapid expansion of the research institutes the number of workers with a gift for summarizing and interpretation has not kept pace with the number of those producing figures and data. And their number, already too small, is still further reduced by the demands made on them for organizing and administrative functions.

There is another aspect of modern advisory work that requires more support by research. Present-day technical facilities enable a much greater number of production factors to be regulated and improved, even including those which not long ago were considered permanent and unchangeable. The use of deepdigging ploughs to bring fertile subsoil to the surface, the use of irrigation techniques, the construction of storage facilities, the use of machinery or other technical equipment, are a few examples. They all are making great new demands on the advisory service staff. A high degree of adaptability and versatility are required and the advisory staff bear a great burden of responsibility, not only because of the enormous financial investments involved but because these investments are intended to serve for a great many years to come.

Again, such radical improvements change the whole outlook of the individual farming enterprise. They call for a much more synthetic view on the part of the advisory officer than do partial improvements, the results of which can be fairly easily predicted. In this, the advisory officer should undoubtedly receive much more support from the research institutes. The increasing specialisation of the research institutes works in the opposite direction, and measures should be taken to make certain research workers available to integrate new discoveries made in all the various branches of science. Plans for the improvement and sanitation of agriculture are becoming increasingly complete and all-embracing, including not only soil improvement and drainage, but also farm size, farm buildings, type of farming, and sometimes even the social structure as well. Research activities should so be directed as to effectively support those who have to cope with these developments.

\section{Conclusions}

The advisory officer should have a place in the system of agricultural research. It keeps him open-minded and obliges him to familiarise himself with new scientific developments. The part played by the advisory service in agricultural research will usually be concentrated on exploratory, developmental and operational research, but they may also have the task of carrying out simple empirical, and even factorial research.

Special precautions should be taken to prevent this decentralization from leading to a diffusion of national research activities.

The research institutes can help the advisory officer by systematizing his empirical experience and knowledge, by presenting the results of research activities in a practical and readily comprehensible form, and by paying attention to the problems of the farm as a whole. 